Article

\title{
The Effect of Logging and Strip Cutting on Forest Floor Light Condition and Following Change
}

\author{
Tomoya Inada $^{1, *}$, Kaoru Kitajima ${ }^{1}$, Suryo Hardiwinoto ${ }^{2}$ and Mamoru Kanzaki ${ }^{1}$ \\ 1 Graduate school of Agriculture, Kyoto University, Kyoto 606-8501, Japan; kaoruk@kais.kyoto-u.ac.jp (K.K.); \\ mkanzaki@kais.kyoto-u.ac.jp (M.K.) \\ 2 Faculty of Forestry, Gadjah Mada University, Bulaksumur, Yogyakarta 55281, Indonesia; \\ suryohardiwinoto@yahoo.com \\ * Correspondence: inada@kais.kyoto-u.ac.jp; Tel.: +81-757-536-361
}

Received: 3 September 2017; Accepted: 31 October 2017; Published: 7 November 2017

\begin{abstract}
We monitored changes in light conditions at a primary forest and two managed forest sites (one with line planting) after reduced-impact logging in Central Kalimantan, Indonesia. We also assessed the effect of the light conditions on seedlings in the planting lines. Hemispherical photographs were taken over a period of 31 months in three $50 \times 50$-m quadrats at each site and in three $100-\mathrm{m}$ transects along the planting lines. The location of each photo was categorized according to the corresponding type of disturbance, including skid trails, logging gaps, and planting lines. Following logging, the level of canopy openness (CO) increased at both managed forest sites and did not differ significantly between the two. However, $\mathrm{CO}$ was greater in skid trails and logging gaps than in planting lines. After 31 months, the mean level of $\mathrm{CO}$ at each managed site had decreased significantly due to the establishment of new seedlings. Correlations between changes in $\mathrm{CO}$ and the growth of planted seedlings suggested that growth was inhibited by the invasion of the new species. However, the level of $\mathrm{CO}$ along the planting lines was greater than that at other disturbed locations. A high level of $\mathrm{CO}$ promoted invasion by new species that colonized the space. Line planting may influence forest dynamics and maintain a high level of CO.
\end{abstract}

Keywords: hemispherical photography; RIL; line planting; light condition; lowland dipterocarp forest

\section{Introduction}

After logging, light conditions on the forest floor are important for the growth of new seedlings. Gaps in the canopy can lead to colonization by a variety of tree seedlings, and the species composition influences the subsequent dynamics [1,2]. In an area disturbed by logging, Macaranga species often invade in response to large openings in the canopy [3-5]. Rapid colonization by particular species (e.g., Macaranga) can prevent ecologically and economically important species (e.g., dipterocarps) from becoming established. Changes in the light conditions following logging are important for predicting how the forest will recover. In Indonesia, reduced-impact logging (RIL) and line planting have been introduced to create sustainable forest management. The success of RIL in minimizing the effect of logging has been demonstrated, showing that it has less impact on the canopy than conventional logging [6-8]. In Indonesia, the line planting system, which involves selective logging using the RIL method, followed by the planting of Shorea species, has been tested for the establishment of sustainable forest management [9]. Following selective logging, 3-m wide strip cutting was performed at 20-25-m intervals, and Shorea seedlings, which belong to the family Dipterocarpaceae, were planted in the lines.

From a comparison between two sites with or without line planting after RIL, the light conditions on the forest floor changed significantly, although there was no difference in mean CO between the two managed forest sites [10]. However, strip cutting may generate differences in subsequent forest floor light conditions. In addition, different types of disturbances associated with logging activities 
(e.g., skid trails created by bulldozers and logging gaps) may affect the subsequent light conditions differently. Conventional selective logging can have an effect on forest light conditions even after 50 years [11]. Therefore, it is important to understand the effects of RIL and line planting on forest light conditions, especially in the period immediately after logging. The light conditions at this time will have an effect on the long-term dynamics of forest recovery. Additionally, light conditions in the planting lines are important for the planted seedlings. The initial light conditions are particularly important for Shorea seedlings. In some line planting tests, seedling mortality was very high during this initial period $[12,13]$. It is also necessary to understand the effects of changes in light conditions so that improvements can be made in line planting methods. Hemispherical photography is a practical method for measuring canopy openness (CO) and assessing the light conditions in a forest [11,14-16]. In this study, hemispherical photography was used to monitor the changes in light conditions at the forest floor from 2011 onward in a primary forest and at two sites with different forest management systems, as well as the effect of light conditions on line-planted seedlings.

\section{Materials and Methods}

\subsection{Study Site}

The study area was the logging concession in Central Kalimantan, Indonesia $\left(00^{\circ} 36^{\prime}-01^{\circ} 10^{\prime} \mathrm{S}\right.$; $111^{\circ} 39^{\prime}-112^{\circ} 25^{\prime}$ E; Figure 1). The mean annual precipitation between 2001 and 2009 was $3240 \mathrm{~mm}$, the altitude was $400-600 \mathrm{~m}$ above sea level, and the vegetation was lowland dipterocarp forest. The study sites were a primary forest (PF) and two managed forest sites. One of the latter two sites was selectively logged (S), and the other was selectively logged and line planted (SL). Selective logging was performed at both the S and SL sites during January 2011. During April 2011, 3-m-wide strip cutting at 25-m intervals was performed from North to South at the SL site. All plants were cleared except large commercially important trees. Dynamic monitoring plots were established at each site, and a tree census was performed between September and November 2011. The basal areas of trees $\geq 10 \mathrm{~cm}$ at the PF, S, and SL sites were 32, 22.9, and $18.5 \mathrm{~m}^{2} /$ ha, respectively.

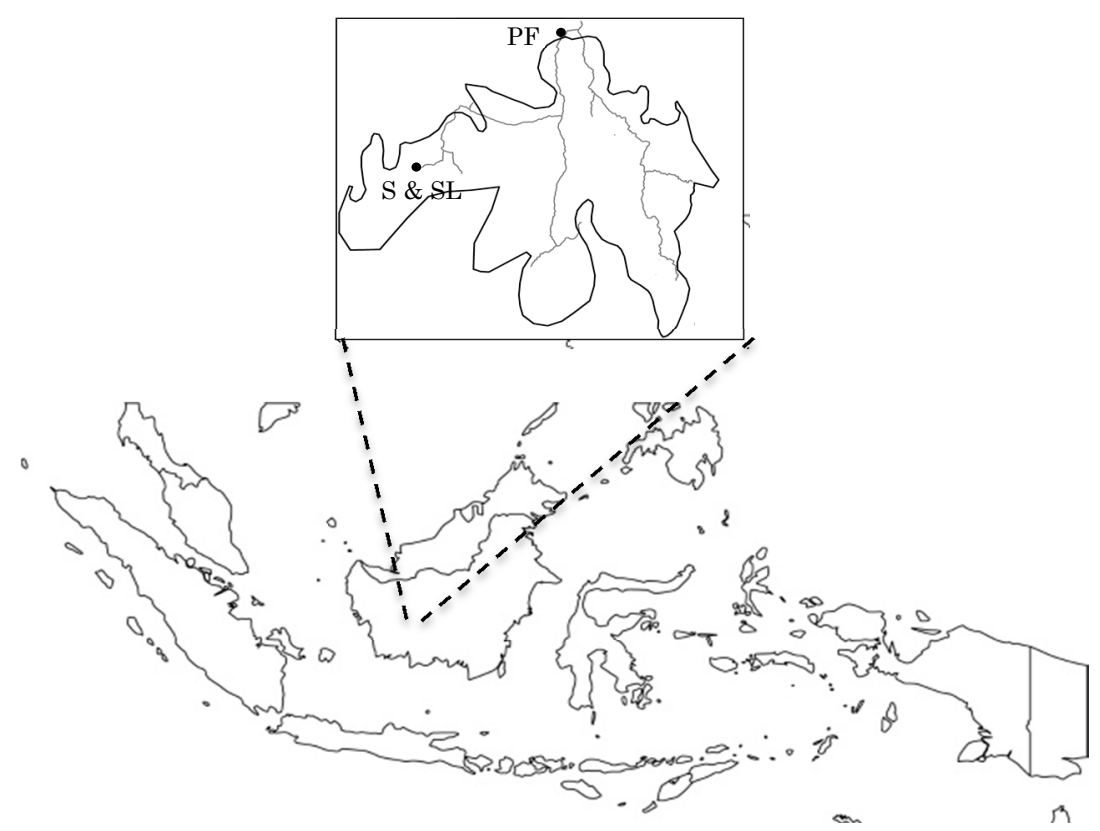

Figure 1. Study area and the location of primary forest (PF), selectively logged (S) and selectively logged and line planted (SL) sites where hemispherical photography was conducted. 


\subsection{Plot Setting}

To monitor the light conditions, three $50 \times 50-\mathrm{m}$ quadrats were set up for hemispherical photography at each site (PF1-3, S1-3, and SL1-3). At the SL site, three planting lines were also marked out (Pline1, Pline2, and Pline3). To assess the impact on light conditions of different logging activities (logging gaps, skid trails, and strip cutting lines), logging trails were also mapped on each quadrat (Figure 2). The size of logging gaps in the quadrates ranged from 100 to $400 \mathrm{~m}^{2}$, and the mean size was $200 \mathrm{~m}^{2}$. With the RIL method, the logging gap did not exceed $500 \mathrm{~m}^{2}$, and pioneer species could invade [17]. The skid trails were approximately 3-4 m wide. Additionally, to assess the response of seedlings to changes in light conditions, a $20 \times 100$-m line transect was set up along a planting line, and a tree census was performed for all trees $>1 \mathrm{~cm}$ in diameter at breast height in 2011 and 2012.

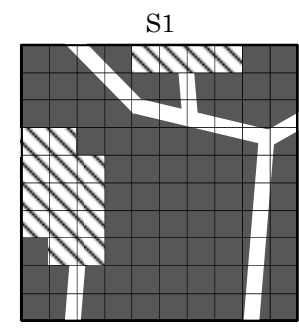

SL1

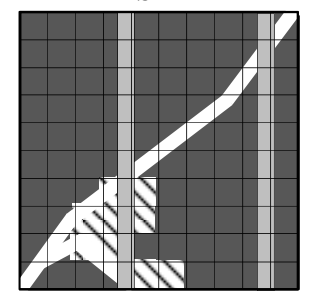

N 5-m grid included in logging gap

Intact from logging activities
$\mathrm{S} 2$

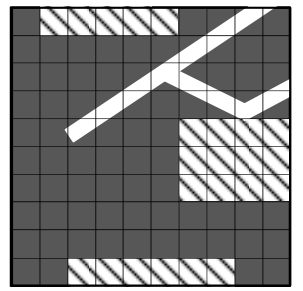

SL2

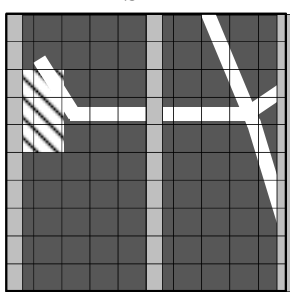

$\square$ Skid trail

Planting line
S3

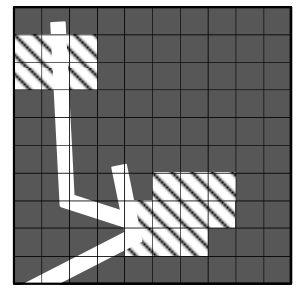

SL3

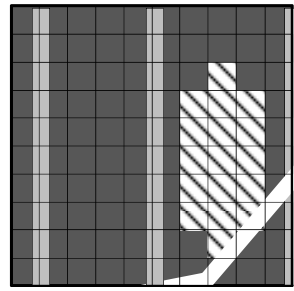

Figure 2. Logging trails in each quadrate at the S and SL sites.

\subsection{Hemispherical Photography and Image Analysis}

Hemispherical photography was performed to assess changes in the light conditions. The photography equipment included a Coolpix 8400 digital camera (Nikon, Tokyo, Japan) with an FC-E9 $0.2 \times$ fisheye converter lens attached (Nikon, Tokyo, Japan). The camera was mounted on a tripod and oriented so that the top of each photograph would face magnetic north. The lens was positioned at a height of $1.2 \mathrm{~m}$, and photographs were taken using the Open-sky Reference Method [18].

Hemispherical photographs were taken in October 2011, October 2012 (i.e., 12 months later), and May 2014 (at 31 months). The photographs were taken from a total of 49 points on a 5-m-interval grid within each $50 \times 50-\mathrm{m}$ quadrat. In addition, a total of 21 photo points were positioned at 5-m intervals for $100 \mathrm{~m}$ along each planting line transect (Figure 3). 

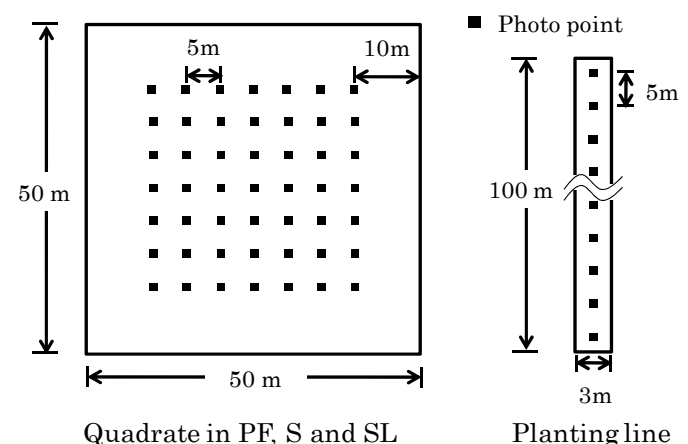

Figure 3. Hemispherical photography setting in the quadrate at the PF, S and SL sites and the planting line transect.

The hemispherical photograph data were analyzed using Gap Light Analyzer software (ver. 2.02; Frazer et al., 1999), which has been used in several previous studies [19]. CO was calculated from the hemispherical photograph taken at each point.

\subsection{Monitoring Planted Seedlings in the Planting Lines}

Following the first assessment of light conditions, Shorea seedlings were planted at 2.5-m intervals at SL sites in December 2011. Seedlings of the species Shorea johorensis were planted in two of the three lines (Plines 1 and 2), and S. leprosula seedlings were planted in the third line (Pline3). The survival and growth of planted trees at 10 months after planting were monitored beginning when the second photographs were taken. Growth was monitored by measuring tree diameters at ground level.

The hemispherical photo points in the planting lines were positioned at 5-m intervals. The seedlings were planted between two photo points. The average $\mathrm{CO}$ between two neighboring photo points was used to evaluate the correlation between light conditions and the growth of the planted seedlings. Multiple regression analysis was performed to assess these correlations. The objective variable was seedling growth, and the explanatory variables were the changes in CO from 2011 to 2012 and from 2011 to 2014, the initial CO in 2011, and the site conditions at the planting points recorded in 2011 (e.g., skid trails or logging gaps) as shown in equation (1). The site conditions were a categorical variable (i.e., assigned values of 0 or 1 ).

Equation:

Seedling growth $(\mathrm{cm})=$ Changes in CO from 2011 to 2012 $(\%)+$ Change in CO from 2011 to 2014(\%) + Initial CO in $2011(\%)+$ Site conditions $(0,1)$

\subsection{Statistical Analysis}

Statistical analysis was performed using SPSS software (SPSS, Chicago, IL, USA). To compare the impact of different types of forest management, the mean CO at each study site, the PF, S, and SL sites, and the planting line, were compared using the Steel-Dwass test. To assess changes in the light conditions, the correlations between the initial CO measurements in 2011 and the reductions observed in 2012 and 2014 were analyzed using Spearman's test. A p-value $<0.05$ was considered statistically significant.

\section{Results}

\subsection{CO Change from 2011 to 2014 at Each Site}

Logging and strip cutting in 2011 had a significant impact on light conditions (Figure 4). The mean $\mathrm{CO}$ for the PF, S, and SL sites and planting lines was $1.79 \pm 0.95 \%, 7.57 \pm 6.63 \%, 7.88 \pm 6.55 \%$, 
and $11.17 \pm 6.6 \%$, respectively. The mean CO was significantly greater at the S and SL sites and at the planting lines compared with the PF site. The difference between the two managed forest sites was not significant. The greatest mean CO was observed in the planting lines (Steel-Dwass test, $p<0.05$ ).

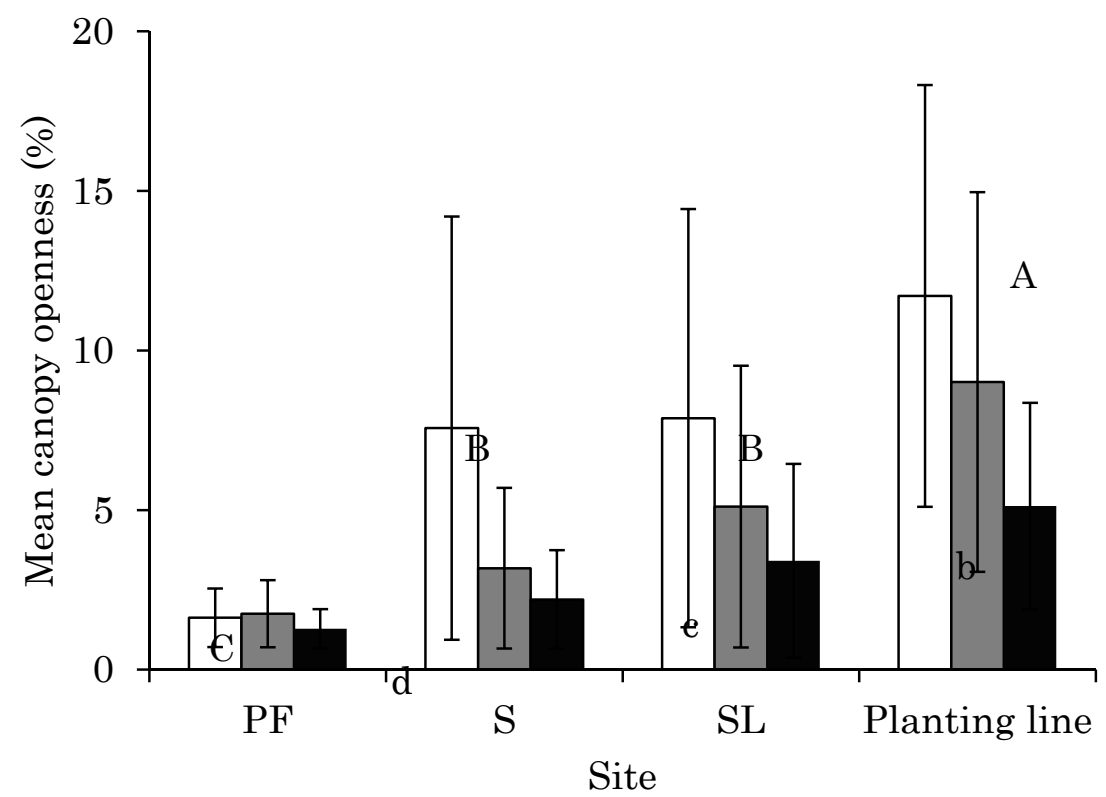

Figure 4. Mean canopy openness (CO) at each site and planting line measured in 2011 (blank bars), 2012 (shaded bars), and 2014 (filled bars). Error bars indicate the standard deviation (S.D.). Different capital and small letters indicate a statistical difference among the three sites and planting line in 2011 and 2014 (Steel-Dwass test, $p<0.05$ ).

After 2011, the mean CO decreased significantly until 2012 and 2014 at the two managed sites and in the planting lines. At 31 months, the mean CO for the PF, S, and SL sites and the planting lines had changed to $1.28 \pm 0.61 \%, 2.2 \pm 1.54 \%, 3.14 \pm 1.69 \%$, and $5.13 \pm 3.23 \%$, respectively. With the exception of the PF site, the mean CO values had decreased significantly at all locations. The mean CO was still greater at the two managed forest sites and the planting lines than at the PF site (Steel-Dwass test, $p<0.05)$, and the difference between the $S$ and SL sites was significant. The greatest mean CO was in the planting lines. The reductions in CO at each photo point in 2012 and 2014 were correlated with the initial CO values recorded in 2011 (Spearman's test, $p<0.01$ ); these correlations were stronger in 2014 than in 2012 (Figure 5).

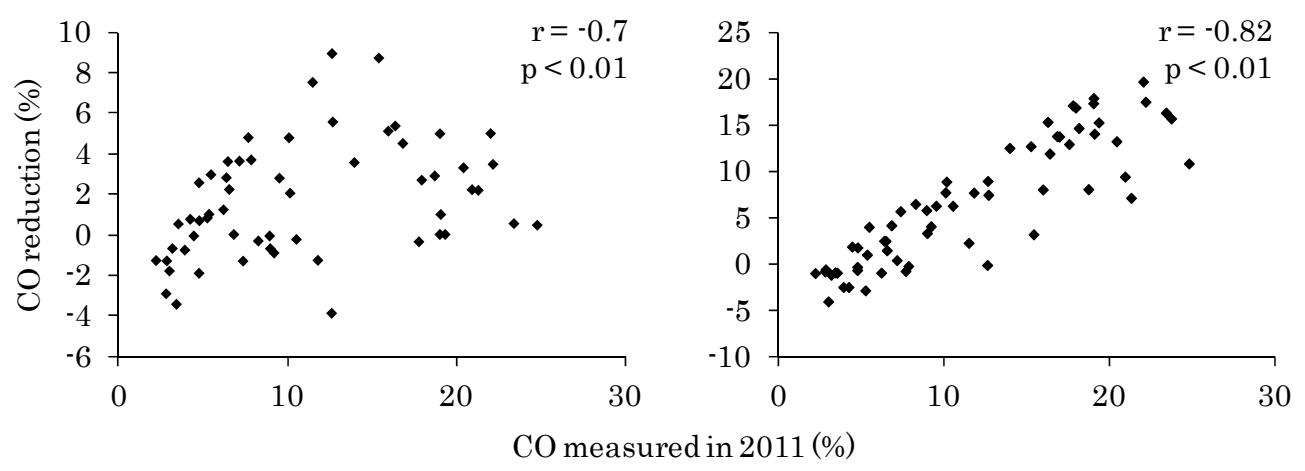

Figure 5. Correlation between the initial CO measured in 2011 and the CO reduction to 2012 (left) and 2014 (right). The correlations were tested using Spearman's method. 
There was a high level of CO in 2011 associated with each type of disturbance, including skid trails, logging gaps, and planting lines (Figure 6).
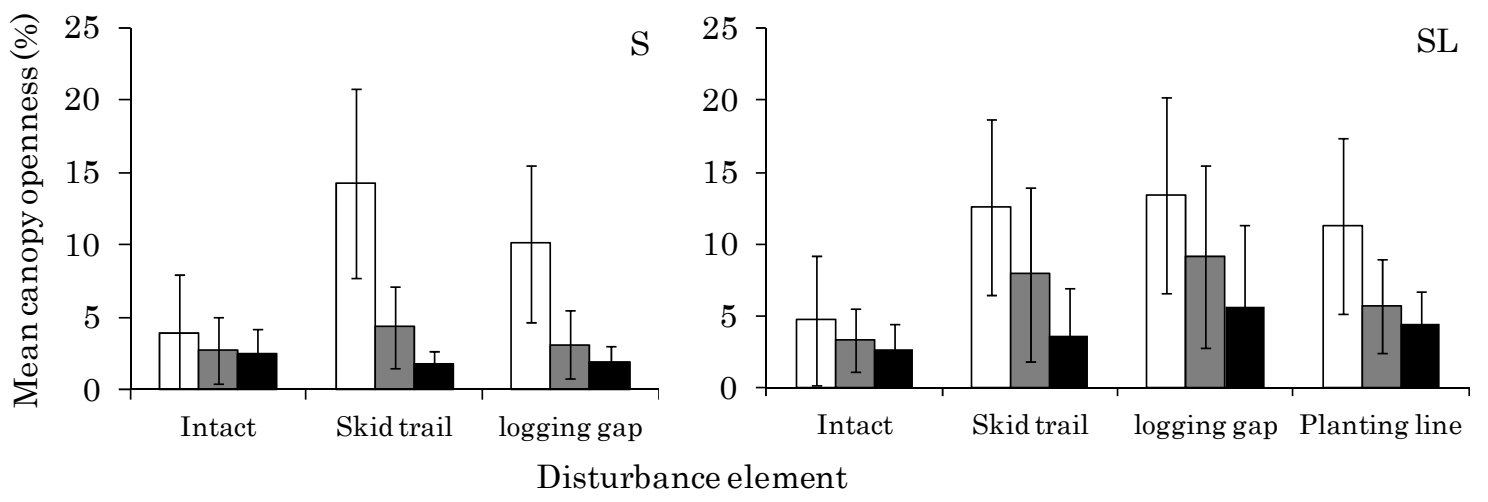

Figure 6. Mean CO under each disturbance element measured in 2011 (blank bars), 2012 (shaded bars), and 2014 (filled bars) at the S and SL sites. Error bars indicate the standard deviation.

The highest level of $\mathrm{CO}$ at the $\mathrm{S}$ site was in the skid trails. At the SL site, there was no difference in $\mathrm{CO}$ between the skid trails and logging gaps, although the mean $\mathrm{CO}$ was slightly lower in the planting lines. By May 2014, the mean CO in the skid trails and logging gaps at the S site had decreased to the same level as those in the intact forest. However, at the SL site, CO remained high in disturbed areas. At the SL3 plot, ferns had become predominant in the logging gaps. This abundance of ferns was not reflected in the photographs, which were taken at a height of $1.3 \mathrm{~m}$, resulting in a high CO value at this site. When the SL3 plot was excluded from consideration, the mean CO at each type of disturbance was slightly higher at the SL than at the S site, and the mean $\mathrm{CO}$ was greatest in the planting lines (Figure 7).

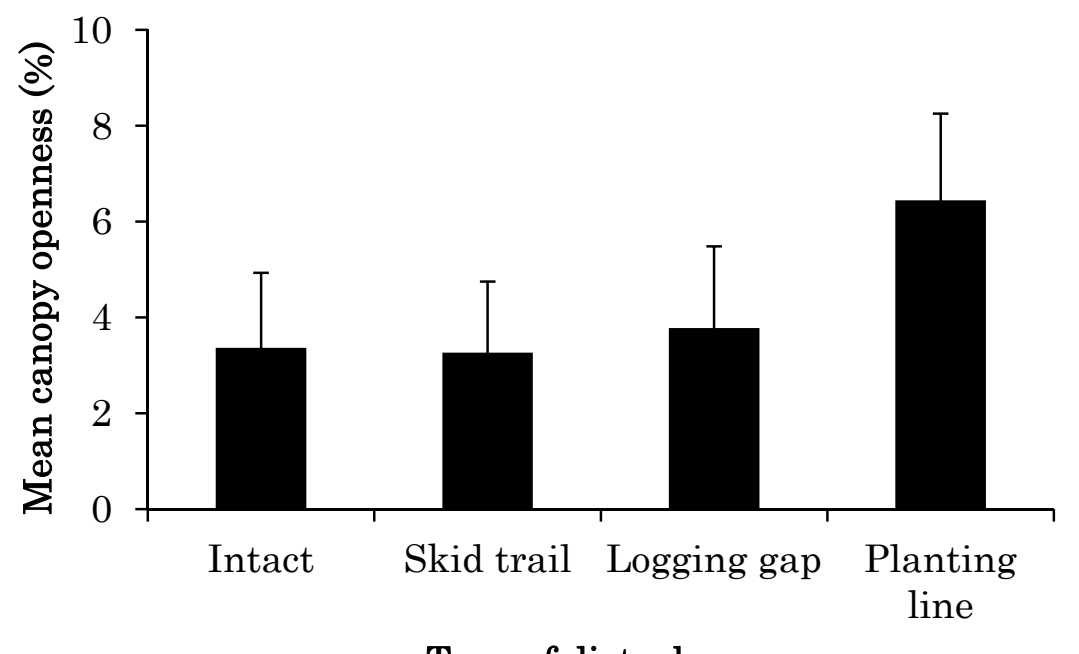

Type of disturbance

Figure 7. Mean O under each disturbance element measured at the SL site excluding plot SL3 in 2014. Error bars indicate the standard deviation.

However, when the three sites and the planting lines were compared, the mean $\mathrm{CO}$ was significantly higher at the SL than at the $\mathrm{S}$ site. This significant difference in mean CO between the S and SL sites appeared after approximately three years. The data from the tree censuses at a planting line in 2011 and 2012 demonstrated that a large number of seedlings $(n=510)$ appeared after 
only one year. These seedlings were abundant along the skid trails, bulldozer passes, and in logging gaps, although were less numerous along the strip cutting line (Figure 8).

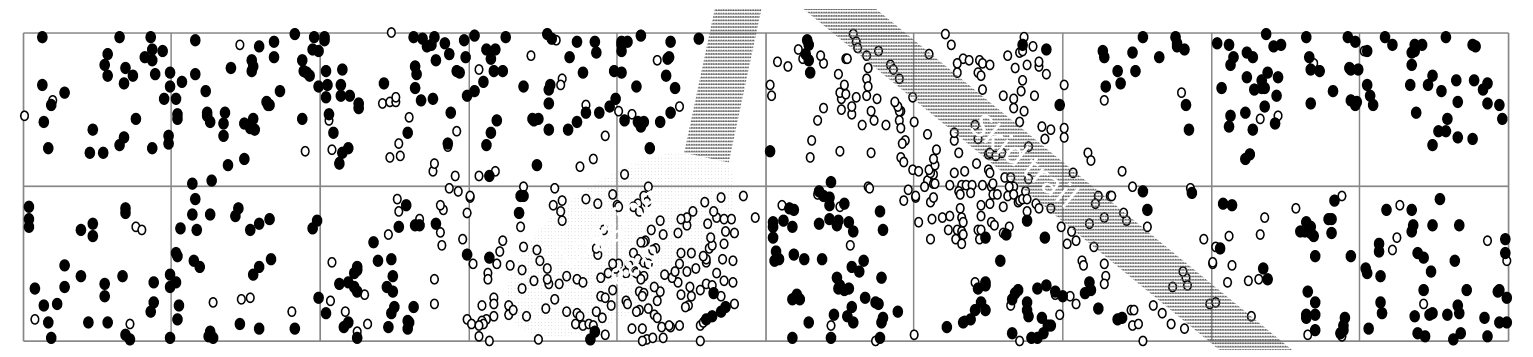

Figure 8. The positions of all trees $>1 \mathrm{~cm}$ diameter at breast height (DBH) in 2011 (filled dots) and seedlings that were newly established up to 2012 (blank dots) in a $20 \times 100 \mathrm{~m}$ line transect set along a planting line.

\subsection{Planted Seedling Growth and Correlation to Changes in Light Conditions}

Between October 2012 and May 2014, the survival rates of the planted species S. johorensis $(n=82)$ and S. leprosula $(n=41)$ were $87 \%$ and $81.8 \%$, respectively. The mean diameter of the S. johorensis and S. leprosula plants increased from $1.1 \pm 0.27 \mathrm{~cm}$ and $0.86 \pm 0.28 \mathrm{~cm}$ to $1.97 \pm 0.56 \mathrm{~cm}$ and $1.43 \pm 0.53 \mathrm{~cm}$, respectively. The mean seedling height increased from $115.7 \pm 38.6 \mathrm{~cm}$ and $254.5 \pm 87.3 \mathrm{~cm}$ to $101.3 \pm 37 \mathrm{~cm}$ and $230.9 \pm 89.3 \mathrm{~cm}$, respectively. Some seedlings were bent or damaged and became stunted. The multiple regression analysis identified no variables that were correlated with diameter and height growth. However, the changes in CO between 2011 and 2012 and changes in seedling diameters between 2012 and 2014 suggested that growth might be suppressed by a decrease in CO (Figure 9). Growth diameter decreased from 2012-2014 in association with a reduction in CO between 2011 and 2012.
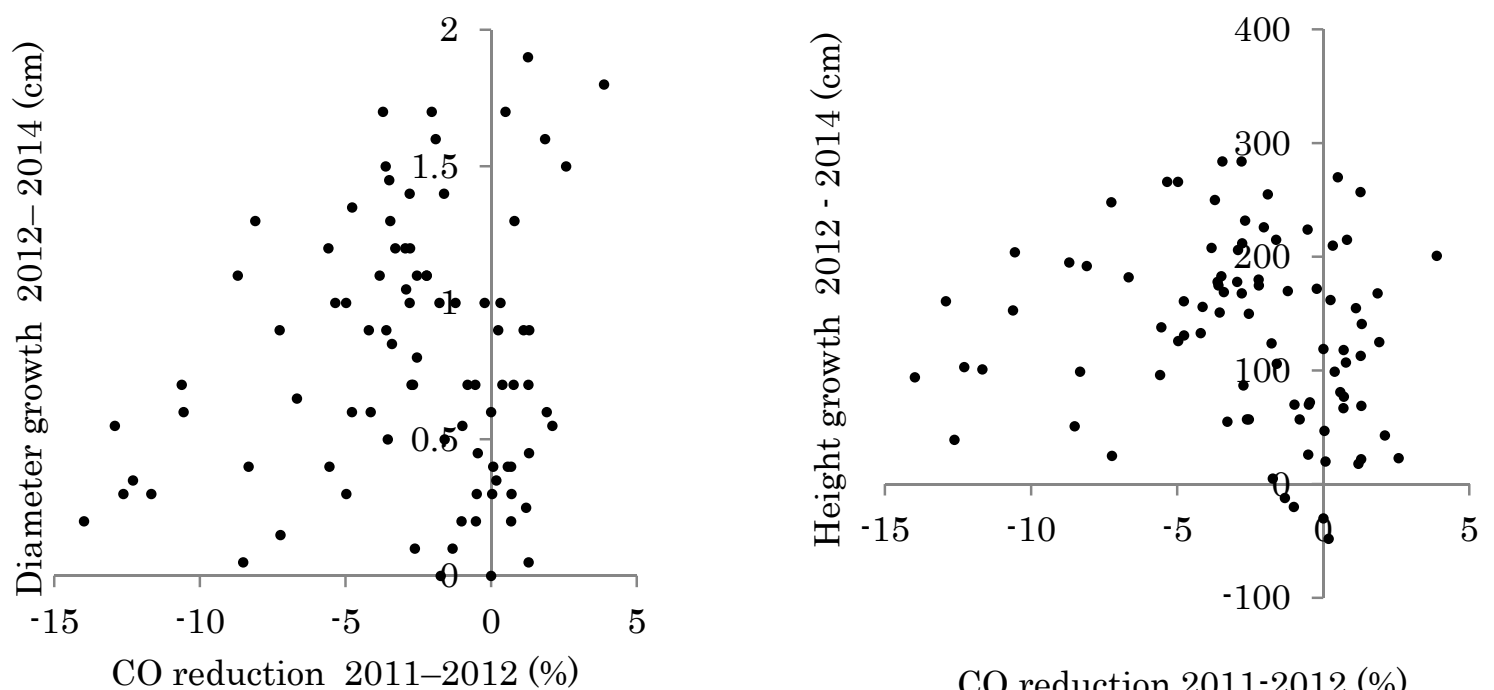

CO reduction 2011-2012 (\%)

Figure 9. Correlation between the CO reduction from 2011 to 2012 at each photo point in the planting line $(n=63)$ and seedling growth from 2012 to 2014 .

\section{Discussion}

\subsection{Changes in Light Conditions after Logging Management}

Our results were consistent with previous research that demonstrated a low level of CO in primary forest environments $[3,11,20]$, largely due to multilayer canopies $[6,16]$. Logging these canopy trees 
significantly alters the light conditions on the forest floor. For 31 months after logging management, $\mathrm{CO}$ values decreased significantly in areas where the level of CO was high in 2011 (Figure 5). After only 31 months, the forest floor was no longer illuminated, even in the large clearings created by logging in 2011. Our tree census along a planting line demonstrated that the large gaps in the canopy generated by logging were closed due to the appearance of new seedlings and not because of crown expansion by neighboring trees. The higher level of $\mathrm{CO}$ provided opportunities for the new seedlings to take over and close the gaps in the canopy. Even in 2012, one year after logging and planting, some seedling heights exceeded $1.2 \mathrm{~m}$. Sometimes, the majority of invading species were ferns, which prevented tree seedlings from becoming established [4].

By May 2014, the mean CO in the S and SL sites differed significantly, regardless of whether line planting was performed after logging. An examination of all the $\mathrm{CO}$ changes that occurred at each type of disturbance (i.e., skid trails, logging gaps, and planting lines) demonstrated that the highest mean levels of CO were in skid trails at the $S$ site in 2011 . When $8-15$ trees/ha were removed, $15-40 \%$ of the area was typically covered by bulldozer tracks [21-23], and plant growth in these skid trails was poor [5]. Therefore, reducing the number of skid trails generated by applying RIL methods might help promote canopy recovery.

Between 2011 and May 2014, the mean level of CO returned to levels typical of intact forest, even in S-site skid trails. In October 2011, the mean level of CO in logging gaps and skid trails at the SL site was greater than that in planting lines. However, by May 2014, the mean level of CO in planting lines was greatest when a plot dominated by ferns was excluded from consideration. When strip cutting was used, the gaps in the canopy remained open. Strip cutting may be less destructive for the forest stand than logging gaps and skid trails. Large commercially important trees were not cleared from the 3-m-wide lanes, and the impact of strip cutting on changes in the light levels reaching the forest floor was probably less than that of logging gaps and skid trails. Seedlings frequently became established in and around skid trails and logging gaps. However, the relatively low impact of line planting on the light conditions produced a higher level of CO compared with other types of disturbance and also a difference between S and SL sites in 2014. Although the effect of strip cutting on forest floor light conditions was not significant, it was prolonged, and it therefore could have an effect on the growth of planted seedlings and the dynamics of canopy recovery.

\subsection{Effect of Changes in Light Conditions on Planted Seedlings}

Excessive light can reduce the growth rate of planted trees by photoinhibition and can also increase their mortality rates by altering the microclimate $[24,25]$. Survival and growth rates are also reduced by low light levels [17]. However, in this study, the observed growth characteristics were not explained by multiple regression analysis, changes in CO from 2011 onward, and the effects of different types of disturbance (e.g., logging gaps and skid trails). Over the three-year monitoring period, reductions in $\mathrm{CO}$ were particularly significant in areas where $\mathrm{CO}$ was initially very high. The growth analysis suggested that decreases in $\mathrm{CO}$ occur because new seedlings appear under high CO and suppress the growth of planted seedlings. Much of the decrease in CO between 2011 and 2012 was probably due to invasion by new species, whose seedlings could be competing for light with the planted seedlings. Here, large numbers of seedlings appeared and inhibited the growth of planted seedlings in 2012. In other planting tests, seedlings often died shortly after they were planted [12,13]. Growth suppression may well have increased the mortality rate among the planted seedlings.

Otherwise, some planted seedlings grew slowly with small $\mathrm{CO}$ reductions (Figure 9). They appeared to be planted in shaded areas, which suppressed their growth.

\section{Conclusions}

The light conditions of planted seedlings differed widely under systematic strip cutting because of the heterogeneity of tree distribution and logging activity traces. Shaded or opened light conditions will lead to growth suppression and high mortality in a few years. 
To improve the line planting system, further examination of moderate light conditions for planted seedlings is necessary. Such an evaluation will help reduce the cost of strip cutting and planting treatment.

Acknowledgments: This study would not have been possible without the support and cooperation of the companies Sari Bumi Kusuma and Wana Subur Lestari. This work was supported by the Strategic Fund for the Promotion of Science and Technology of the Japan Science and Technology Agency (project title: Creation of a paradigm for the sustainable use of tropical rainforest with intensive forest management and advanced utilization of forest resources), JSPS KAKENHI grant number 22251004, and a Grant-in-Aid for JSPS Fellows, grant number 252464, and partly supported by Japan Science and Technology Agency (JST), Collaboration Hubs for International Research Program (CHIRP) within the framework of the Strategic International Collaborative Research Program (SICORP).

Author Contributions: Suryo Hardiwinoto conceive and arranged the experiments; Tomoya Inada, Kaoru Kitajima and Mamoru Kanzaki analyzed the data and wrote the paper.

Conflicts of Interest: The authors declare no conflict of interest.

\section{References}

1. Kuusipalo, J.; Jafarsidik, Y.; Ådjers, G.; Tuomela, K. Population dynamics of tree seedlings in a mixed dipterocarp rainforest before and after Logging and crown liberation. For. Ecol. Manag. 1996, 81, 85-94. [CrossRef]

2. Denslow, J.S. Tropical rainforest gaps and tree species diversity. Annu. Rev. Ecol. Syst. 1987, 18, 431-451. [CrossRef]

3. Nicotra, A.B.; Chazdon, R.L.; Iriarte, S.V.B. Spatial heterogeneity of light and woody seedling regeneration in tropical wet forests. Ecology 1999, 80, 1908-1926. [CrossRef]

4. Slik, J.W.F.; Verburg, R.; Keßler, P.J.A. Effects of Fire and Selective Logging on the Tree Species Composition of Lowland Dipterocarp Forest in East Kalimantan, Indonesia. Biodivers. Conserv. 2002, 11, 85-98. [CrossRef]

5. Howlett, B.E.; Davidson, D.W. Effects of seed availability, site conditions, and herbivory on pioneer recruitment after logging in Sabah, Malaysia. For. Ecol. Manag. 2003, 184, 369-383. [CrossRef]

6. Romell, E.; Hallsby, G.; Karlsson, A. Forest floor light conditions in a secondary tropical rain forest after artificial gap creation in Northern Borneo. Agric. For. Meteorol. 2009, 149, 929-937. [CrossRef]

7. Putz, F.E.; Sist, P.; Fredericksen, T.S.; Dykstra, D. Reduced-impact logging: Challenges and opportunities. For. Ecol. Manag. 2008, 256, 1427-1433. [CrossRef]

8. Putz, F.E.; Zuidema, P.A.; Synnott, T.; Peña-Claros, M.; Pinard, M.A.; Sheil, D.; Vanclay, J.K.; Sist, P.; Gourlet-Fleury, S.; Griscom, B.; et al. Sustaining conservation values in selectively logged tropical forests: The attained and the attainable. Conserv. Lett. 2012, 5, 296-303. [CrossRef]

9. Pamoengkas, P. Potentialities of line planting technique in rehabilitation of logged over area referred to species diversity, growth and soil quality. Biodiversitas 2010, 11, 34-39. [CrossRef]

10. Inada, T.; Ano, W.; Hardiwinoto, S.; Sadono, R.; Setyanto, P.E.; Kanzaki, M. Effects of logging and line planting treatment on canopy openness in logged-over forests in Bornean lowland dipterocarp forest. Tropics 2013, 22, 89-98. [CrossRef]

11. Yamada, T.; Yoshioka, A.; Hashim, M.; Liang, N.; Okuda, T. Spatial and temporal variations in the light environment in a primary and selectively logged forest long after logging in Peninsular Malaysia. Trees 2014, 28, 1355-1365. [CrossRef]

12. Ådjers, G.; Hadengganan, S.; Kuusipalo, J.; Nuryanto, K.; Vesa, L. Enrichment planting of dipterocarps in logged-over secondary forests: Effect of width, direction and maintenance method of planting line on selected Shorea species. For. Ecol. Manag. 1995, 73, 259-270. [CrossRef]

13. Matsune, K.; Soda, R.; Sunyoto; Tange, T.; Sasaki, S.; Suparno. Planting Techniques and Growth of Dipterocarps in an Abandoned Secondary Forest in East Kalimantan, Indonesia. In Plantation Technology in Tropical Forest Science; Susuki, K., Ishii, K., Sakurai, S., Sasaki, S., Eds.; Springer: Tokyo, Japan, 2006; pp. 221-229.

14. Chazdon, R.L.; Field, C.B. Photographic estimation of photosynthetically active radiation: Evaluation of a computerized technique. Oecologia 1987, 73, 525-532. [CrossRef] [PubMed] 
15. Clark, D.B.; Clark, D.A.; Rich, P.M.; Weiss, S.; Oberbauer, S.F. Landscape-scale evaluation of understory light and canopy structure: Methods and application in a neotropical lowland rain forest. Can. J. For. Res. 1996, 26, 747-757. [CrossRef]

16. Silbernagel, J.; Moeur, M. Modeling canopy openness and understory gap patterns based on image analysis and mapped tree data. For. Ecol. Manag. 2001, 149, 217-233. [CrossRef]

17. Brokaw, N.V.L. Treefalls, regrowth, and community structure in tropical forests. In The Ecology of Natural Disturbance and Patch; Picket, A., White, P.S., Eds.; Academic Press: New York, NY, USA, 1985.

18. Tani, A.; Ito, E.; Tsujino, M.; Araki, M.; Kanzaki, M. Threshold determination by reference to open sky overcomes photographic exposure error in indirect leaf area index estimation. Jpn. J. For. Environ. 2011, 53, 41-52.

19. Jarčuška, B. Methodological overview to hemispherical photography, demonstrated on an example of the software GLA. Folia Oecol. 2008, 35, 66-69.

20. Bischoff, W.; Newbery, D.M.; Lingenfelder, M.; Schnaeckel, R.; Petol, G.H.; Madani, L.; Ridsdale, C.E. Secondary succession and dipterocarp recruitment in Bornean rain forest after logging. For. Ecol. Manag. 2005, 218, 174-192. [CrossRef]

21. Chai, D.N.P. Enrichment planting in Sabah. Malays. For. 1975, 38, 271-277.

22. Jusoff, K. A survey of soil disturbance from tractor logging in a hill forest of Peninsular Malaysia. In Malaysian Forestry and Forest Products Research; Appanah, S., Ng, F.S., Ismail, R., Eds.; Forest Research Institute Malaysia: Kepong, Malaysia, 1991; pp. 16-21.

23. International Timber Trade Organization (ITTO). Pre-Project Study Report: Enrichment Planting; International Timber Trade Organization: Yokohama, Japan, 1989.

24. Sasaki, S.; Mori, T. Growth responses of dipterocarp seedlings to light. Malays. For. 1981, 44, 319-345.

25. Van Oorschot, G.; Van Winkel, I.; Moura-Costa, P. The use of GIS to study the influence of site factors in enrichment planting with dipterocarps. In Proceedings of the 5th Round Table Conference on Dipterocarps, Chiang Mai, Thailand, 7-10 November 1994; Appanah, S., Khoo, K.C., Eds.; Forest Research Institute: Kuala Lumpur, Malaysia, 1996; pp. 267-278.

(C) 2017 by the authors. Licensee MDPI, Basel, Switzerland. This article is an open access article distributed under the terms and conditions of the Creative Commons Attribution (CC BY) license (http:/ / creativecommons.org/licenses/by/4.0/). 